\title{
Sulfurospirillum arcachonense sp. nov., a New Microaerophilic Sulfur-Reducing Bacterium
}

\author{
KAI FINSTER, ${ }^{*}$ WERNER LIESACK, ${ }^{2}$ AND B. J. TINDALL ${ }^{3}$ \\ Institute of Biological Sciences, Department of Microbial Ecology, University of Århus, Arhus C, Denmark, ${ }^{1}$ and Max- \\ Planck-Institut für terrestrische Mikrobiologie, D-35043 Marburg, ${ }^{2}$ and DSMZ-Deutsche Sammlung von \\ Mikroorganismen und Zellkulturen GmbH, D-38124 Braunschweig, ${ }^{3}$ Germany
}

The isolation of a new motile, gram-negative, heterotrophic, sulfur-reducing, microaerophilic, vibrioid bacterium, strain F1F6, from oxidized marine surface sediment (Arcachon Bay, French Atlantic coast) is described. Hydrogen (with acetate as the carbon source), formate (with acetate as the carbon source), pyruvate, lactate, $\alpha$-ketoglutarate, glutarate, glutamate, and yeast extract supported growth with elemental sulfur under anaerobic conditions. Apart from $\mathrm{H}_{2}$ and formate, the oxidation of the substrates was incomplete. Microaerophilic growth was supported with hydrogen (acetate as the carbon source), formate (acetate as the carbon source), acetate, propionate, pyruvate, lactate, $\alpha$-ketoglutarate, glutamate, yeast extract, fumarate, succinate, malate, citrate, and alanine. The isolate grew fermentatively with fumarate, succinate being the only organic product. Elemental sulfur and oxygen were the only electron acceptors used. Vitamins or amino acids were not required. The isolate was oxidase, catalase, and urease positive. Comparative 16S rDNA sequence analysis revealed a tight cluster consisting of the validly described species Sulfurospirillum deleyianum and the strains SES-3 and CCUG 13942 as the closest relatives of strain F1F6 (level of sequence similarity, 91.7 to $92.4 \%$ ). Together with strain F1F6, these organisms form a novel lineage within the epsilon subclass of proteobacteria clearly separated from the described species of the genera Arcobacter, Campylobacter, Wolinella, and Helicobacter. Due to the phenotypic characteristics shared by strain F1F6 and $S$. deleyianum and considering their phylogenetic relationship, we propose the inclusion of strain F1F6 in the genus Sulfurospirillum, namely, as $S$. arcachonense sp. nov. Based on the results of this study, an emended description of the genus Sulfurospirillum is given.

The ability to use elemental sulfur as an electron acceptor for organotrophic or lithotrophic growth has been reported from a relatively large number of metabolically versatile microbial groups of the domains Bacteria and Archaea (15, 21, 22, $24,33,37,38,47)$. Sulfur-reducing bacteria can be placed in two distinct physiological groups, which include genera belonging to different phylogenetic lineages. The first group (group 1) includes species of obligate anaerobic bacteria belonging to the genera Desulfuromonas (33), Desulfurella (2), Desulfuromusa (22), Geobacter (5), and Pelobacter (24). With the exception of those members of the genus Pelobacter that have been tested for the ability to grow with sulfur as an electron acceptor (24), all members of group 1 completely oxidize their substrates (complete oxidizers), releasing exclusively $\mathrm{CO}_{2}$ and $\mathrm{H}_{2} \mathrm{~S}$. A second group (group 2) includes members of the genera Wolinella (49), Campylobacter (37), Shewanella (27) (originally described as a member of the genus Alteromonas [30]), and Sulfurospirillum $(37,48)$, as well as isolates which have not been characterized taxonomically, such as free-living "Campylobacter-like organisms," (DSM 806 = CCUG 13942) (19) and the dissimilatory selenate- and arsenate-reducing strain SES-3 $(21,31)$ that has been tentatively named "Geospirillum barnesii" $(23,41)$. These species have in common the abilities to grow at low oxygen concentrations and to oxidize organic substrates incompletely with elemental sulfur as the electron acceptor (incomplete oxidizers). Among the sulfate-reducing bacteria, in particular, members of the genera Desulfovibrio and Desulfomicrobium (1) have the ability to couple the reduction of sulfur to growth. Members of both genera are obligate

\footnotetext{
*Corresponding author. Fax: 45-86-127191. E-mail: Kai@bio.aau
} .dk. anaerobes, like the group 1 sulfur reducers. It is noteworthy that all of the bacterial groups under discussion belong to the Proteobacteria. However, the sulfate-reducing bacteria mentioned above and group 1 sulfur reducers, except Desulfurella acetivorans (34), form distinct lineages within the delta subclass of the Proteobacteria, whereas all microaerophilic Group 2 sulfur reducers are placed either in the gamma subclass (Shewanella spp.) or in the epsilon subclass of the Proteobacteria (Campylobacter spp., Sulfurospirillum spp. [results of this study], and Wolinella spp.).

In this communication, we report on the enrichment, isolation, and genotypic and phenotypic characterization of strain F1F6, a marine, microaerophilic, sulfur-reducing, gram-negative bacterium.

\section{MATERIALS AND METHODS}

Source of inoculum. Oxidized iron-rich surface sediment from a Zostera noltiiovergrown mud flat (Arcachon, French Atlantic Coast) served as the inoculum for a dilution series used to enumerate formate-consuming sulfur reducers. Six strains were isolated from the highest dilution in which growth occurred $\left(10^{6}\right)$. When it became apparent that the isolates closely resembled each other phenotypically, only one strain, designated F1F6, was studied in detail.

Medium and cultivation. The defined mineral medium used was prepared and handled as described by Finster and Bak (11). Substrates were added from sterile stock solutions with glass pipettes prior to inoculation. Elemental sulfur was sterilized as described by Pfennig and Biebl (33). Amorphous Fe(III)-oxyhydroxide was prepared by titration of an acidic $\mathrm{FeCl}_{3}$ solution with $\mathrm{NaOH}$ to $\mathrm{pH}$ 7. The suspension was sterilized by autoclaving. Organic and inorganic substrates were sterilized by either autoclaving or filtration through sterile $0.2-\mu \mathrm{m}$-pore-size filters into sterile glass bottles. Cultures were incubated at $26^{\circ} \mathrm{C}$ in the dark.

Enrichment cultures and isolation. On the basis of the physical and chemical measurements carried out to characterize the natural environment under study, it was shown that the following environmental conditions prevailed: (i) high iron content, (ii) positive redox potential, and (iii) no free hydrogen sulfide (17). We therefore prepared dilution series containing $8 \mathrm{ml}$ of defined marine minimal medium, highly purified elemental sulfur, $1 \mathrm{ml}$ of a $0.3 \mathrm{M}$ suspension of amorphous $\mathrm{Fe}(\mathrm{III})$-oxyhydroxide, formate $(20 \mathrm{mM})$, and acetate $(1 \mathrm{mM})$. The test 
tubes were incubated at $20^{\circ} \mathrm{C}$ in the dark and examined daily for growth. Sulfurreducing bacteria were isolated by repeated application of deep agar dilutions (30). $\mathrm{Fe}$ (III)-oxyhydroxide-containing solid media in test tubes were prepared as described by Finster et al. (12).

In addition to microscopic examination, isolates were checked for purity in complex medium containing yeast extract $(0.1 \%)$, fumarate $(5 \mathrm{mM})$, glucose $(5$ $\mathrm{mM})$, and pyruvate $(5 \mathrm{mM})$, as well as on blood agar plates under oxic and microoxic $\left(3 \% \mathrm{O}_{2}\right)$ conditions.

Substrate tests. The spectrum of electron donors and electron acceptors utilized by strain F1F6 was determined in 20 -ml screw-cap test tubes supplemented with the appropriate substrate combination and inoculated with bacteria precultivated on fumarate. The inoculum was $1 \%$ (vol/vol). In electron donor tests, either sulfur or oxygen ( $3 \%$ in the gas phase) served as the electron acceptor. Test medium with elemental sulfur also contained $1 \mathrm{ml}$ of $\mathrm{Fe}$ (III)oxyhydroxide. The reduction of elemental sulfur was monitored by observing blackening of the iron precipitate. Growth was monitored by microscopic examination. Experiments with oxygen as the electron acceptor were carried out with $120-\mathrm{ml}$ serum bottles sealed with rubber stoppers. They contained $20 \mathrm{ml}$ of inoculated medium and were incubated on a bottle roller $(120 \mathrm{rpm})$. Inoculated test tubes and serum bottles containing elemental sulfur or oxygen, respectively, but no electron donor served as controls. Lactate, pyruvate, malate, fumarate, maleate, glutamate, oxalacetate, and aspartate (all at $5 \mathrm{mM}$ ) were also tested without an electron acceptor. Inoculated test tubes without electron donors and acceptors served as controls. The ability to grow by fermentation of glucose, mannitol, inositol, rhamnose, sucrose, melibiose, amygdalin, and arabinose was tested with API 20E test kits (Biomérieux, Marcy-l'Etoile, France) under oxygenfree conditions. Electron acceptors were tested with formate $(20 \mathrm{mM})$ and acetate $(1 \mathrm{mM})$ as the electron donor and carbon source, respectively. Inoculated test tubes without an electron acceptor served as controls. The incubations were carried out at $26^{\circ} \mathrm{C}$ in the dark. All tests were carried out in duplicate, and tubes were incubated for 4 weeks and periodically examined for sulfide production and growth

Growth parameters. Carbon sources, the vitamin requirement, and the $\mathrm{pH}$, salt, and temperature tolerance of the isolate were studied by growth tests in which the change in optical density of the culture medium or the accumulation of hydrogen sulfide was monitored. All experiments were carried out in duplicate. The temperature range for growth of the isolate was determined by incubating inoculated test tubes in an insulated aluminium temperature gradient block with a minimum temperature of $4^{\circ} \mathrm{C}$ and a maximum temperature of $50^{\circ} \mathrm{C}$. Incubation was stopped after a maximum of 6 weeks. Generation times were calculated from the increase in the optical density of the culture over time. When the strain was grown with formate, acetate, and elemental sulfur, the generation time was derived from a semilogarithmic plot of the sulfide concentrations as a function of time. A straight line was interpreted as exponential growth of the bacterial population. The presence of catalase was assayed by addition of a few drops of a $3 \% \mathrm{H}_{2} \mathrm{O}_{2}$ solution to a grown culture of strain F1F6. Cytochrome oxidase was assayed with prefabricated test strips by following the instructions of the supplier (Merck, Darmstadt, Germany).

Extraction of respiratory lipoquinones and polar lipids. Respiratory lipoquinones and polar lipids were extracted from $100 \mathrm{mg}$ of freeze-dried cell material by using the two-stage method described by Tindall $(44,45)$. Polar lipids were extracted by adjusting a methanol- $0.3 \%$ aqueous $\mathrm{NaCl}$ phase to give a chloroform-methanol- $0.3 \%$ aqueous $\mathrm{NaCl}$ mixture $(1: 2: 0.8$, vol/vol/vol $)$. The extraction solvent was stirred, and the cell debris was pelleted by centrifugation. Polar lipids were recovered in the chloroform phase by adjusting the chloroformmethanol- $0.3 \%$ aqueous $\mathrm{NaCl}$ mixture to a ratio of $1: 1: 0.9$ (vol $/ \mathrm{vol} / \mathrm{vol}$ ).

Analysis of respiratory lipoquinones. Respiratory lipoquinones were separated into their different classes (menaquinones and ubiquinones) by thin-layer chromatography on silica gel (Macherey-Nagel no. 805023 ) with hexane-tertbutylmethylether $(9: 1, \mathrm{vol} / \mathrm{vol})$ as the solvent. UV-absorbing bands corresponding to menaquinones or ubiquinones were removed from the plate and further analyzed by high-performance liquid chromatography (HPLC). This step was carried out on an LDC Analytical (Thermo Separation Products) HPLC apparatus fitted with a reverse-phase column ( 2 by $125 \mathrm{~mm}, 3 \mu \mathrm{m}, \mathrm{RP}_{18}$; MachereyNagel) with methanol as the eluant. Respiratory lipoquinones were detected at $269 \mathrm{~nm}$.

Analysis of polar lipids. Polar lipids were separated by two-dimensional silica gel thin-layer chromatography (Macherey-Nagel no. 818 135). The first direction was developed in chloroform-methanol-water $(65: 25: 4, \mathrm{vol} / \mathrm{vol} / \mathrm{vol})$, and the second was developed in chloroform-methanol-acetic acid-water (80:12:15:4, vol/ $\mathrm{vol} / \mathrm{vol} / \mathrm{vol}$ ). Total lipid material and specific functional groups were detected by using dodecamolybdophosphoric acid (total lipids), Zinzadze reagent (phosphate), ninhydrin (free amino groups), periodate-Schiff ( $\alpha$-glycols), Dragendorff's test (quaternary nitrogen), and anisaldehyde-sulfuric acid (glycolipids).

Fatty acid analysis. Fatty acids were analyzed as the methyl ester derivatives prepared from $10 \mathrm{mg}$ of dry cell material. Cells were subjected to differentia hydrolysis to detect ester-linked and non-ester-linked (amide-bound) fatty acids (45a). Fatty acid methyl esters were analyzed by gas chromatography with using a nonpolar capillary column $(0.2 \mu \mathrm{m}$ by $25 \mathrm{~m})$ and a flame ionization detector. The run conditions were an injection and detector port temperature of $300^{\circ} \mathrm{C}$, an inlet pressure of $60 \mathrm{kPa}$, a split ratio of $50: 1$, an injection volume of $1 \mu \mathrm{l}$, and a temperature program ranging from 130 to $310^{\circ} \mathrm{C}$ at a rate of $4^{\circ} \mathrm{C} / \mathrm{min}$.
Chemical analysis. Volatile fatty acids, lactate, succinate, and fumarate were analyzed by ion-exclusion chromatography with an HPLC system as described recently (12). Sulfide was measured by the methylene blue method as described by Cline (6).

$\mathbf{G}+\mathbf{C}$ content of genomic DNA. Determination of the $\mathrm{G}+\mathrm{C}$ content of the DNA was carried out at the Deutsche Sammlung von Mikroorganismen und Zellkulturen GmbH, Braunschweig, Germany, by using HPLC separation and UV detection (43). Calibration and determination of $G+C$ content were performed as described by Mesbah et al. (26).

Comparative 16S rDNA sequence analysis. DNA isolation, PCR-mediated amplification of the almost complete $16 \mathrm{~S}$ rRNA gene, and sequence analysis were done as described previously (22). In addition to that of strain F1F6, the 16S rDNA sequence of Sulfurospirillum deleyianum 5175 (DSM $6946^{\mathrm{T}}$ ) was determined for reference. The $16 \mathrm{~S}$ rDNA sequences were added to a database of about 6,000 complete or partial $16 \mathrm{~S}$ rRNA primary structures of bacteria $(25,35$, 46) by using the automatic alignment tool of the ARB program package (42). The alignment was checked and, if necessary, manually corrected. The phylogenetic positions of strain F1F6 and $S$. deleyianum were deduced by comparing their 16S rDNA sequences with reference sequences from members of the epsilon subclass of the Proteobacteria for which at least 1,400 determined nucleotide positions were available (103 sequences). The overall tree topology was evaluated for a sequence stretch ranging from positions 28 through 1475 (Escherichia coli 16S rRNA numbering [4]) by using distance matrix and maximumparsimony methods [PHYLIP; reference [10]). In addition, different subsets of about 30 sequences were used to reconstruct phylogenetic trees by applying the maximum-likelihood method (fastDNAml [25]). These sets of data varied with respect to the reference sequences used, as well as the alignment positions included. To avoid possible treeing artifacts caused by nucleotide sequence positions that are subject to multiple mutational changes and/or not to align unambiguously, only those positions which contained identical residues in at leas $50 \%$ of the alignment positions were used for phylogenetic analyses. The usefulness of this invariance criterion for the inclusion and exclusion, respectively, of nucleotide sequence positions from the treeing analysis has been discussed in detail by Friedrich et al. (13). The variabilities of individual alignment positions were determined by using the appropriate tool of the ARB package. The base frequencies were calculated based on the complete set of available epsilon proteobacterial sequences and based on different subsets comprising equivalen numbers of reference sequences belonging to the major subgroups of the epsilon subclass. This resulted in the use of 1323 to 1352 nucleotide sequence positions for reconstruction of the phylogenetic trees. The statistical significance of interior branching points was tested in bootstrap analyses by using the maximum parsimony (PHYLIP; 100 data resamplings) and neighbor-joining (ARB; 1,000 data resamplings) methods. All phylogenetic analyses were done by using software in the ARB package.

Nucleotide sequence accession numbers. The $16 \mathrm{~S}$ rDNA sequences of strain F1F6 and $S$. deleyianum 5175 (DSM 6946 ${ }^{\mathrm{T}}$ ) have been deposited in the EMBL, GenBank, and DDBJ nucleotide sequence databases under accession numbers Y11561 and Y13671, respectively. All of the reference sequences used are part of the ARB software package (16S rRNA database: tree_1400_feb97).

\section{RESULTS}

Enrichment and isolation. After an incubation period of 3 weeks, in all tubes the red $\mathrm{Fe}$ (III)-oxyhydroxide had reacted to black iron sulfide. The majority of the highly motile curved rods which were dominant in all dilutions of the most-probable-number series was present in the black precipitate. The number of free-swimming cells was increased after particles of the precipitate were crushed under the coverslip. The highest positive dilution was chosen to inoculate agar dilution series. Well-separated, whitish, slightly filamentous colonies from the fifth dilution step were withdrawn and grown in iron-containing liquid medium. The procedure was repeated until culture purity was obtained. Interestingly, a different colony morphology and colony pigmentation appeared when the agar deeps were supplemented with either fumarate as the sole substrate or succinate and oxygen (3\% in the gas phase). In both cases, the colonies were lens shaped with entire edges and had yellow-brown pigmentation. Large colonies were surrounded by a halo consisting of less densely packed cells. No difference, however, was observed at the cellular level. Colonies transferred from one of the three agar media to liquid medium containing either fumarate, succinate, and oxygen (3\% in the gas phase) or formate, acetate, sulfur, and $\mathrm{Fe}(\mathrm{III})$-oxyhydroxide grew equally well compared to colonies that were transferred from agar medium to liquid medium identical in com- 


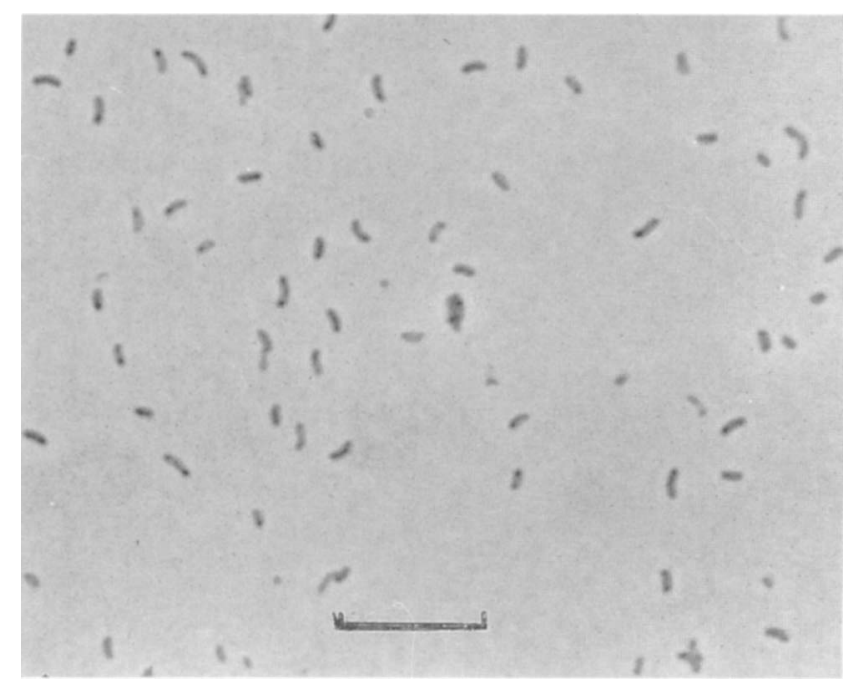

FIG. 1. Phase-contrast photomicrograph of $S$. arcachonense F1F6 grown with fumarate. Bar, $5 \mu \mathrm{m}$.

position. Anaerobic or microaerophilic (3\% oxygen in the gas phase) growth occurred neither on agar plates containing basal medium and fumarate, on blood agar plates, nor in liquid McConkey medium.

Morphology. Cells of strain F1F6 were vibrioid, 1.0 to 2.5 $\mu \mathrm{m}$ long, and $0.3 \mu \mathrm{m}$ wide (Fig. 1). In growing cultures, spirilla consisting of two or more single cells were often observed. Cells were highly motile by a polar or subpolar flagellum. The cells stained gram negative.

Carbon sources and electron donors. (i) Growth with elemental sulfur. The substrate concentration used was $5 \mathrm{mM}$ if not indicated otherwise. Strain F1F6 was able to grow on hydrogen or formate in the presence of acetate or another organic carbon source (see below for carbon sources), lactate, pyruvate, $\alpha$-ketoglutarate, glutarate, glutamate, and yeast extract $(0.15 \mathrm{mM})$ when elemental sulfur served as the electron acceptor. The following electron donors were not used with elemental sulfur as the electron acceptor: acetate, propionate, butyrate, valerate, myristinate $(2 \mathrm{mM})$, benzoate $(1 \mathrm{mM})$, trimethoxybenzoate $(1 \mathrm{mM})$, cyclohexanecarboxylate $(2 \mathrm{mM})$, vanillin $(2 \mathrm{mM})$, pyrogallol $(2 \mathrm{mM})$, pyrimidine $(2 \mathrm{mM})$, phenylpropionate $(2 \mathrm{mM}), p$-cresol $(1 \mathrm{mM})$, succinate, fumarate, malate, maleate ( $2 \mathrm{mM})$, pimelate, adipate, methanol, ethanol, $n$-propanol, glycerol, glycolate $(2 \mathrm{mM})$, glyoxylate $(2 \mathrm{mM})$, acetone, ethylene glycol, oxalate $(1 \mathrm{mM})$, formaldehyde (1 $\mathrm{mM}$ ), betaine, cholinchloride, alanine, aspartate, mannitol, glucose, gluconate $(2 \mathrm{mM})$, and starch $(0.1 \%)$. The strain was not able to grow autotrophically with elemental sulfur and $\mathrm{Fe}(\mathrm{III})$-oxyhydroxide, nor was the strain able to disproportionate elemental sulfur.

Of all the substrates tested, only fumarate was fermented. Succinate was the sole organic product. The following substrates were not fermented (concentrations in API 20E test kit are unknown): lactate, pyruvate, malate, aspartate, maleate, glutamate, oxalacetate, glucose, mannitol, inositol, sorbitol, rhamnose, sucrose, melibiose, amygdalin, and arabinose.

(ii) Growth with oxygen. In the presence of oxygen (3\% in the headspace) as the electron acceptor, the following compounds sustained growth: $\mathrm{H}_{2}$ (acetate as the carbon source), acetate, propionate, succinate, pyruvate, lactate, $\alpha$-ketoglutarate, glutamate, citrate, malate, alanine, and yeast extract. Growth with formate (with acetate as the carbon source) was observed only with $1 \%$ or less oxygen in the headspace. At higher oxygen concentrations, growth was inhibited.

In contrast, oxygen concentrations of up to $15 \%$ in the gas phase supported growth with succinate as the organic substrate in agitated cultures. Culture growth was initiated by clump formation by the inoculated cells. After some days, the turbidity of the medium increased, indicating more free-swimming cells, as verified by microscopy. In nonagitated culture bottles, strain F1F6 grew with succinate as the substrate under an atmosphere containing $20 \%$ oxygen.

When bacteria were grown with fumarate in the presence of oxygen, succinate was produced as an intermediate. Acetate, propionate, lactate, fumarate, and succinate were oxidized completely with oxygen as the electron acceptor. The degradation of the other substrates was not studied in detail. The following substrates did not sustain growth with oxygen $(3 \%)$ in the gas phase: glutarate, propionate, butyrate, methanol, ethanol, glycerol, starch, and betaine.

The strain was not able to utilize sulfate, thiosulfate, sulfite ( $2 \mathrm{mM}$ ), dimethyl sulfoxide, trimethylamine $N$-oxide, nitrate, nitrite $(2 \mathrm{mM}), \mathrm{Fe}(\mathrm{III})$-oxyhydroxide, Fe-citrate, malate, or aspartate as an electron acceptor. The generation times of strain F1F6 (measured at $22^{\circ} \mathrm{C}$ ) with different substrate combinations were as follows: formate (acetate as the carbon source) plus elemental sulfur, $33 \mathrm{~h}$; fumarate, $16 \mathrm{~h}$; fumarate plus oxygen ( $3 \%$ in the gas phase), $12 \mathrm{~h}$; succinate plus oxygen ( $3 \%$ in the gas phase), $32 \mathrm{~h}$.

(iii) Organic carbon sources. Strain F1F6 was not able to grow anaerobically by sulfur reduction with formate and $\mathrm{CO}_{2}$ alone but required an additional organic carbon source. Acetate could be replaced with propionate, citrate, succinate, malate, or alanine. Glucose, glycerol, or ethanol was not used as a carbon source. Cultures with acetate, citrate, or succinate grew equally well, and signs of growth (blackening of the iron phase and clumping of the precipitate) were observed 3 days after inoculation. A lag phase of 7 days was observed in cultures grown on propionate, while cultures with malate or alanine as the carbon source started to grow after 16 days.

pH, salt, and temperature ranges and optima. Strain F1F6 grew within a $\mathrm{pH}$ range of 6.1 to 8.2 with an optimum between 7.0 and 7.4. The lowest temperature at which growth occurred was $8^{\circ} \mathrm{C}$, and the highest was $30^{\circ} \mathrm{C}$. The optimum temperature was $26^{\circ} \mathrm{C}$.

Strain F1F6 required both $\mathrm{NaCl}$ and $\mathrm{MgCl}_{2} \cdot 6 \mathrm{H}_{2} \mathrm{O}$ for growth. Growth was inhibited with less than $0.6 \%$ or more than $4 \% \mathrm{NaCl}$ in the medium. The optimum $\mathrm{NaCl}$ concentration was between 1.2 and $2 \%$. At least $0.1 \% \mathrm{MgCl}_{2} \cdot 6 \mathrm{H}_{2} \mathrm{O}$ was required. The maximum concentration was not determined. Growth was only slightly inhibited with $2.1 \% \mathrm{MgCl}_{2} \cdot 6 \mathrm{H}_{2} \mathrm{O}$ compared to the optimum concentration $(0.1$ to $0.3 \%)$. Vitamins were not required for optimal growth. Strain F1F6 was oxidase and catalase positive.

G $+\mathbf{C}$ content of the genomic DNA. The $\mathrm{G}+\mathrm{C}$ ratio of the DNA of strain F1F6 was $32.0 \mathrm{~mol} \%$.

Quinones and lipids. The only respiratory lipoquinones detected were naphthoquinones, as determined by thin-layer chromatography. Two bands were evident on the thin-layer plates, with $R_{f}$ values suggesting the presence of a menaquinone and a monomethylmenaquinone. This was confirmed by HPLC separation of the naphthoquinones, resulting in the detection of two compounds only, a menaquinone with six isoprenoid units (MK-6; 83\%) and a monomethylmenaquinone with six isoprenoid units (MMK-6; 17\%).

Polar lipids. Only phospholipids were detected, and they comprised two major components, phosphatidylglycerol and phosphatidylethanolamine, together with a smaller amount of 


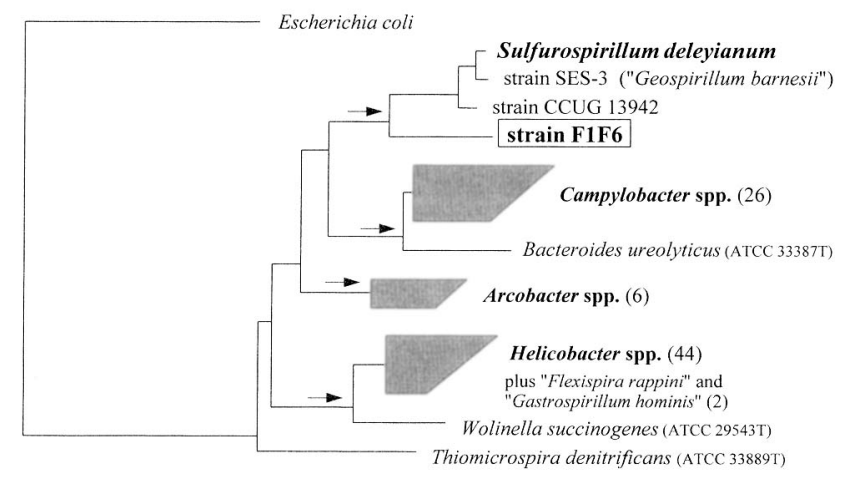

0.10

FIG. 2. 16S rDNA-based phylogenetic dendrogram reconstructed for strain F1F6, S. deleyianum 5175, and 84 reference organisms comprising the major subgroups within the epsilon subclass of the Proteobacteria and E. coli as an outgroup reference. The tree topology was derived by performing distance matrix analyses (calculation of the distance matrix, Jukes-Cantor equation [18]; tree construction, neighbor-joining method [36]) and corrected in accordance with the results of maximum-parsimony and maximum-likelihood analyses. The presence of four major subgroups characterized by $S$. deleyianum, strain SES-3 ( $G$. bamesii), and strain F1F6 (I); Campylobacter spp. (II); Arcobacter spp. (III); and Helicobacter spp. plus Wolinella succinogenes (IV) was confirmed by bootstrap values as high as 95 through 99 (percentage of outcome) in neighbor-joining tests and 100 in maximum-parsimony tests for the respective interior branching points (arrows). The triangles indicate the phylogenetic depth of the genera Arcobacter, Campylobacter, and Helicobacter plus related organisms, respectively. Each number in parentheses is the number of reference sequences of the respective genus used to reconstruct the phylogenetic tree. The scale bar represents the estimated number of base changes per nucleotide sequence position.

a third amino- and phosphate-positive lipid, with an $R_{f}$ value similar to that of lysophosphatidylethanolamine.

Fatty acids. Analysis of the fatty acid pattern revealed as predominant compounds 14:0 (2.7\%), 14:1 (3.2\%), 16:0 $(31.0 \%), 16: 1(40.8 \%), 18: 0(20.8 \%)$, and 18:1 (0.6\%). Trace amounts of $15: 0,17: 0$, and $3 \mathrm{OH}$ 14:0 were also detected. All major fatty acids appeared to be ester linked. The $3 \mathrm{OH} 14: 0$ was amide linked. Particularly interesting, however, was the failure to detect significant quantities of hydroxy fatty acids $(<2 \%$ in strain $\mathrm{F} 1 \mathrm{~F} 6)$.

Phylogenetic analysis. Phenotypic characteristics shared by strain F1F6 and $S$. deleyianum 5175 suggested that it would be appropriate to include the $16 \mathrm{~S}$ rDNA sequence of the latter organism in this study. Integration of these two sequences into the available database of bacterial $16 \mathrm{~S}$ rRNA sequences showed that both strains belong to the epsilon subclass of the Proteobacteria. All treeing analyses not only confirmed the phylogenetic affiliation of both organisms but also indicated that they form, together with strains SES-3 and CCUG 13942, a novel lineage clearly separated from members of the genera Arcobacter, Campylobacter, and Helicobacter plus Wolinella which comprises the major subgroups of cultured organisms within the epsilon subclass of proteobacteria (Fig. 2). Within the phylogenetic radiation of the Sulfurospirillum subgroup, strain F1F6 forms a slightly separate branch whereas the other three organisms represent a tight cluster with overall $16 \mathrm{~S}$ rRNA similarity values above $97.5 \%$. The corresponding values between strain F1F6 and $S$. deleyianum, strain SES-3, and strain CCUG 13942 are $92.0,91.7$, and $92.5 \%$, respectively. In contrast, the level of sequence similarity between strain F1F6 and representatives of the other major lineages within the epsilon subclass of proteobacteria ranges between 82.9 and $88.2 \%$.

\section{DISCUSSION}

Based on a detailed polyphasic approach which included physiological, chemotaxonomic, and phylogenetic investigations, the new isolate, strain F1F6, was identified as a true member of the epsilon subclass of proteobacteria. $S$. deleyianum 5175 represents its closest validly described relative. The overall $16 \mathrm{~S}$ rRNA dissimilarity value of $8.0 \%$ between both microorganisms suggests the taxonomic rank of a new genus for strain F1F6. However, due to the common phenotypic characteristics in conjunction with their phylogenetic affiliation, we describe strain F1F6 as the type strain of a new species of the genus Sulfurospirillum, namely, as $S$. arcachonense sp. nov.

Another interesting result of this study is the finding of a close relationship between $S$. deleyianum and strain SES-3. The $16 \mathrm{~S}$ rRNA sequences of both microorganisms share an overall similarity of $99 \%$ and thus can be considered as phylogenetic twins. In recent publications, the dissimilatory $\mathrm{Fe}(\mathrm{III})$-, selenate-, and arsenate-reducing strain SES-3 has tentatively been named "Geospirillum barnesii" $(23,41)$. However, the genus name "Geospirillum" is in conflict with the validly described taxon Sulfurospirillum $(16,37)$, which should be considered in the further taxonomic description of strain SES-3.

Chemotaxonomy. Although menaquinones and monomethylmenaquinones have been reported in members of the genus Shewanella (29), members of this genus also contain ubiquinones. The only organisms known to produce exclusively menaquinones and monomethylmenaquinones are members of the genus Thermoplasma and members of the genera Arcobacter, Campylobacter, Helicobacter, and Wolinella $(7,8,28)$. Members of the genus Thermoplasma produce MK-7 and MMK-7, whereas the majority of those members of the genera Arcobacter, Campylobacter, Helicobacter, and Wolinella examined to date produce MK-6 and MMK-6. Exceptions within the members of the Campylobacter-Helicobacter-Arcobacter complex include some species which produce a menaquinone with an unknown structural modification in the side chain (28). $S$. deleyianum has also been shown to produce MK-6 and MMK-6 in proportions similar to those found in strain F1F6 (9). Thus, in the absence of ether-linked lipids, an organism found to contain only menaquinones and monomethylmenaquinones has to be tentatively assigned to the Campylobacter-Helicobacter-Arcobacter complex.

The fatty acid pattern of strain F1F6 showed a number of features which appear to be shared by the limited number of strains belonging to the Campylobacter-Helicobacter-Arcobacter complex which have been studied with respect to their fatty acid composition $(3,14,20)$. All of the orgarisms examined contained 14:0, 16:0,18:0, and 18:1 $\omega 7 \mathrm{c}$, a combination which appears to be distinctive within the Proteobacteria. Various subgroups are defined by the presence of fatty acids such as $12: 014: 1 \omega 7 \mathrm{c}$, and $16: 1 \omega 7 \mathrm{c}$. While the majority of strains examined in previous studies also contained 3-hydroxy fatty acids, various subgroups included those organisms containing 3-OH 12:0 and 3-OH 16:0, only 3-OH 14:0, 3-OH14:0 and $3-\mathrm{OH} 16: 0$, or $3-\mathrm{OH} 18: 0$, indicating the potential for using fatty acids in the taxonomy of this group. Significantly, strain F1F6 contained all of the fatty acids determined to be characteristic of the Campylobacter-Helicobacter-Arcobacter complex but was also distinctive in containing the fatty acid 14:1 (a fatty acid not commonly found in those species examined) and contained no significant quantities of 3-hydroxy fatty acids. The presence of trace amounts of 3-OH 14:0 was indicative of the vestiges of a compound which is otherwise fairly widely distrib- 
uted within this group of organisms. No data on the fatty acid composition of $S$. deleyianum is available.

Practically no data on the polar lipid composition of members of the Campylobacter-Helicobacter-Arcobacter complex is available, making any comparisons difficult.

In conclusion, the results of the respiratory lipoquinone, polar lipid, and fatty acid analysis of strain F1F6 indicate that it is chemically similar in many respects to other members of the Campylobacter-Helicobacter-Arcobacter complex studied to date. This provides independent evidence in support of the $16 \mathrm{~S}$ rDNA sequence. While the chemical data available on members of the Campylobacter-Helicobacter-Arcobacter complex is rather scant, it supports the inclusion of strain F1F6 in the same phyletic group as members of the genera Campylobacter, Helicobacter, Arcobacter, and Wolinella. However, some of the chemical features of strain F1F6 (particularly the fatty acid pattern) indicate that it belongs to a distinct phyletic group within the Campylobacter-Helicobacter-Arcobacter complex.

Phenotypic comparison with $S$. deleyianum 5175 and strain SES-3. The relatively close evolutionary affiliation of strain F1F6 with $S$. deleyianum is also reflected by a number of common phenotypic characteristics (37): (i) curved-to-spiral morphology, (ii) the ability to use elemental sulfur for organotrophic or lithotrophic growth, (iii) the ability to use oxygen as an electron acceptor, (iv) the ability to reduce fumarate to succinate, (v) the inability to use sulfate as an electron acceptor, (vi) the requirement for an organic carbon source, (vii) the inability to ferment glucose, (viii) a mesophilic temperature range, and (ix) oxidase activity.

Strain F1F6, however, differs from $S$. deleyianum in the following traits: (i) the lower $\mathrm{G}+\mathrm{C}$ content of the DNA (38 to 40 mol\% for $S$. deleyianum versus $32 \mathrm{~mol} \%$ for strain F1F6) (this is still in a range which is not in conflict with the proposal to place both organism in the same genus) (40), (ii) the presence of catalase, (iii) the inability to use nitrate or nitrite and sulfite, thiosulfate, or DMSO as an electron acceptor, (iv) the inability to ferment malate, (v) the ability to use lactate, (vi) the ability to use $\mathrm{H}_{2}$, acetate, or propionate with oxygen as an electron donor, and (vii) the ability to grow in the presence of $1 \%$ glycine and $3.5 \% \mathrm{NaCl}$.

With "G. barnesii" SES-3, strain F1F6 shares $(21,31)$ (i) the curved morophology, (ii) the ability to use elemental sulfur, fumarate, and oxygen for organotrophic growth, and (iii) the inability to use sulfate. In contrast to "G. barnesii" SES-3, strain F1F6 was unable to use nitrate, nitrite, thiosulfate, trimethylamine $N$-oxide, and Fe(III). Growth of strain F1F6 by arsenate and selenate reduction was not tested.

Taxonomy. On the basis of phenotypic and genotypic data, we propose that strain F1F6 be included in the genus Sulfurospirillum as the type strain of a new species, for which we propose the name $S$. arcachonense, with $S$. deleyianum as the closest validly described relative.

Description of Sulfurospirillum arcachonense sp. nov. Sulfurospirillum arcachonense (ar.ca.cho.nen' se. M. L. adj. arcachonense, pertaining to the city of Arcachon, French Atlantic coast, the locality from which the strain was isolated). Curved cells are $0.3 \mu \mathrm{m}$ wide and 1.0 to $2.5 \mu \mathrm{m}$ long. Gram negative. Motile by polar flagellum. Colonies in deep agar cultures are whitish, round, and filamentous with elemental sulfur as an electron acceptor. With oxygen or fumarate, colonies are lens shaped and yellow-brownish.

The $\mathrm{pH}$ range is 6.1 to 8.2 ; optimum, 7.0 to 7.4 . The temperature range is 8 to $30^{\circ} \mathrm{C}$; growth optimum, $26^{\circ} \mathrm{C}$. The salinity range is 0.6 to $4.0 \% \mathrm{NaCl}$; optimum growth occurs in the presence of 1.2 to $2.0 \% \mathrm{NaCl}$. At least $0.1 \% \mathrm{MgCl}_{2} \cdot 6 \mathrm{H}_{2} \mathrm{O}$ was required.
Microaerophilic growth: in agitated cultures growth at $15 \%$ oxygen and in nonagitated cultures growth at $20 \%$ oxygen in the gas phase with succinate as the electron donor; no growth at $>1 \%$ oxygen in the gas phase with formate as the electron donor.

Oxygen or elemental sulfur served as an electron acceptor; fumarate was fermented. Nitrate, nitrite, thiosulfate, sulfate, Fe(III) oxyhydroxide, and dimethyl sulfoxide are not used as electron acceptors. Formate, acetate, propionate, succinate, fumarate, lactate, $\alpha$-ketoglutarate, glutamate, citrate, malate, alanine, and yeast extract are oxidized with oxygen as the electron acceptor. With elemental sulfur as the electron acceptor, hydrogen, formate, lactate, pyruvate, $\alpha$-ketoglutarate, glutarate, glutamate, and yeast extract serve as electron donors. An organic carbon source is required. Vitamins are not required.

MK-6 and MMK-6 are the sole quinones, with MK-6 predominating. The fatty acids comprise $14: 0(2.7 \%), 14: 1(3.2 \%)$, $16: 0(31.0 \%), 16: 1(40.8 \%), 18: 0(20.8 \%)$, and 18:1 $(0.6 \%)$, with trace amounts of 15:0, 17:0, and $3 \mathrm{OH}$ 14:0. The polar lipids comprised phosphatidylglycerol and phosphatidylethanolamine, together with a third phospholipid tentatively identified as lysophosphatidylethanolamine. The $\mathrm{G}+\mathrm{C}$ content of the DNA is $32.0 \mathrm{~mol} \%$.

Isolated from oxidized surface sediment of a $Z$. noltii-overgrown intertidal mud flat near Arcachon, France.

Strain F1F6 (DSMZ 9755) is the type strain.

\section{ACKNOWLEDGMENTS}

Kai Finster thanks Pierre Caumette and the staff of the marine station of Arcachon for their hospitality during the sampling campaign. Kai Finster is indebted to Niels Peter Revsbech and Norbert Pfennig for support and advice. We thank Sonja Fleissner for technical assistance.

The project was financed by the EU project Coastal Lagoon Eutrophication and Anaerobic Processes (CLEAN) under contract EV5V-CT92-008, by the Danish Committee on Biotechnology, and by the Bundesministerium für Bildung, Wissenschaft, Forschung und Technologie (contract 03111221).

\section{REFERENCES}

1. Biebl, H., and N. Pfennig. 1977. Growth of sulfate-reducing bacteria with sulfur as electron acceptor. Arch. Microbiol. 112:115-117.

2. Bonch-Osmolovskaya, E. A., T. G. Solokova, N. A. Kostrikina, and G. A. Zavarzin. 1990. Desulfurella acetivorans gen. nov. and sp. nov., a new thermophilic sulfur-reducing eubacterium. Arch. Microbiol. 153:151-155.

3. Brondz, I., and I. Olsen. 1991. Multivariate analyses of cellular fatty acids in Bacteroides, Prevotella, Porphyromonas, Wolinella, and Campylobacter spp. J. Clin. Microbiol. 29:183-189.

4. Brosius, J., M. L. Palmer, P. J. Kennedy, and H. F. Noller. 1978. Complete nucleotide sequence of a 16S ribosomal RNA gene from Escherichia coli. Proc. Natl. Acad. Sci. USA 75:4801-4805.

5. Caccavaco, F., Jr., D. J. Lonegran, D. R. Lovley, M. Davies, J. F. Stolz, and M. J. McInerney. 1994. Geobacter sulfurreducens sp. nov., a hydrogen- and acetate-oxidizing dissimilatory metal-reducing microorganism. Appl. Environ. Microbiol. 60:3752-3759.

6. Cline, J. D. 1969. Spectrophotometric determination of hydrogen sulfide in natural waters. Limnol. Oceanogr. 14:454-458.

7. Collins, M. D., and T. A. Langworthy. 1983. Respiratory quinone composition of some acidophilic bacteria. Syst. Appl. Microbiol. 4:295-304.

8. Collins, M. D., M. Costas, and R. J. Owen. 1984. Isoprenoid quinone composition of representatives of the genus Campylobacter. Arch. Microbiol. 137:168-170.

9. Collins, M. D., and F. Widdel. 1986. Respiratory quinones of sulphatereducing and sulphur-reducing bacteria: a systematic investigation. Syst. Appl. Microbiol. 8:8-18

10. Felsenstein, J. 1993. PHYLIP (phylogeny inference package), version 3.5c Department of Genetics, University of Washington, Seattle.

11. Finster, K., and F. Bak. 1993. Complete oxidation of propionate, valerate, succinate, and other organic compounds by newly isolated types of marine, anaerobic, mesophilic, gram-negative, sulfur-reducing eubacteria. Appl. Environ. Microbiol. 59:1452-1460.

12. Finster, K., W. Liesack, and B. J. Tindall. 1997. Desulfospira joergensenii, 
gen. nov., sp. nov., a new sulfate-reducing bacterium isolated from marine surface sediment. Syst. Appl. Microbiol. 20:201-208.

13. Friedrich, M., N. Springer, W. Ludwig, and B. Schink. 1996. Phylogenetic positions of Desulfofustis glycolicus gen. nov., sp. nov., and Syntrophobotulus glycolicus gen. nov., sp. nov., two new strict anaerobes growing with glycolic acid. Int. J. Syst. Bacteriol. 46:1065-1069.

14. Goodwin, C. S., W. McConnell, R. K. McCulloch, C. McCullough, R. Hill, M. A. Bronsdon, and G. Kasper. 1989. Cellular fatty acid composition of Campylobacter pylori from primates and ferrets compared with those of other campylobacters. J. Clin. Microbiol. 27:938-943.

15. Huber, R., and K. O. Stetter. 1992. The order Thermoproteales, p. 677-683. In A. Balows, G. Trüper, M. Dworkin, W. Harder, and K. H. Schleifer (ed.), The prokaryotes, 2nd ed., vol. 1. Springer, New York, N.Y.

16. International Committee on Systematic Bacteriology. 1993. Validation of the publication of new names and new combinations previously effectively published outside the IJSB. List no. 44. Int. J. Syst. Bacteriol. 43:188-189.

17. Isaksen, M., and K. Finster. 1992. Sulphate reduction in the root zone of the seagrass Zostera noltii on the intertidal flats of a coastal lagoon (Arcachon, France). Mar. Ecol. Prog. Ser. 137:187-194.

18. Jukes, T. H., and C. R. Cantor. 1969. Evolution of protein molecules, p. 21-132. In H. N. Munro (ed.), Mammalian protein metabolism, vol. 3. Academic Press, Inc., New York, N.Y.

19. Laanbroek, H. J., J. T. Lambers, W. M. deVos, and H. Veldkamp. 1977. L-Aspartate fermentation by a free-living Campylobacter species. Arch. Microbiol. 117:109-114.

20. Lambert, M. A., C. M. Patton, T. J. Barrett, and C. W. Moss. 1987. Differentiation of Campylobacter and Campylobacter-like organisms by cellular fatty acid composition. J. Clin. Microbiol. 25:706-713.

21. Laverman, A. M., J. S. Blum, J. K. Schaefer, E. J. P. Phillips, D. R. Lovley, and R. S. Oremland. 1995. Growth of strain SES-3 with arsenate and other diverse electron acceptors. Appl. Environ. Microbiol. 61:3556-3561.

22. Liesack, W., and K. Finster. 1994. Phylogenetic analysis of five strains of gram-negative, obligate anaerobic, sulfur-reducing bacteria and the description of Desulfuromusa gen. nov., including Desulfuromusa kysingii sp. nov., Desulfuromusa bakii sp. nov., and Desulfuromusa succinoxidans sp. nov. Int. J. Syst. Bacteriol. 44:753-758.

23. Lonergan, D. J., H. L. Jenter, J. D. Coates, E. J. P. Phillips, T. M. Schmidt, and D. R. Lovley. 1996. Phylogenetic analysis of dissimilatory Fe(III)-reducing bacteria. J. Bacteriol. 178:2402-2408.

24. Lovley, D. R., E. J. P. Phillips, D. J. Lonergan, and P. K. Widman. 1995 $\mathrm{Fe}(\mathrm{III})$ and $\mathrm{S}^{0}$ reduction by Pelobacter carbinolicus. Appl. Environ. Microbiol. 61:2132-2138.

25. Maidak, B. L., G. J. Olsen, N. Larsen, R. Overbeek, M. J. McCaughey, and C. R. Woese. 1996. The ribosomal database project (RDP). Nucleic Acids Res. 24:82-85.

26. Mesbah, M., U. Premachandran, and W. B. Whitman. 1989. Precise measurement of the $\mathrm{G}+\mathrm{C}$ content of deoxyribonucleic acid by high-performance liquid chromatography. Int. J. Syst. Bacteriol. 39:159-167.

27. Moser, D. P., and K. H. Nealson. 1996. Growth of the facultative anaerobe Shewanella putrefaciens by elemental sulfur reduction. Appl. Environ. Microbiol. 62:2100-2105.

28. Moss, C. W., M. A. Lambert-Fair, M. A. Nicholson, and G. O. Guerrant 1990. Isoprenoid quinones of Campylobacter cryaerophila, $C$. cinaedi, $C$. fennelliae, C. hyointestinalis, C. pylori, and "C. upsaliensis." J. Clin. Microbiol. 28:395-397.

29. Moule, A. L., and S. G. Wilkinson. 1987. Polar lipids, fatty acids, and isoprenoid quinones of Alteromonas putrefaciens (Shewanella putrefaciens). Syst. Appl. Microbiol. 9:192-198.

30. Myers, C. R., and K. H. Nealson. 1988. Bacterial manganese reduction and growth with manganese oxide as sole electron acceptor. Science 240:1319 1321.

31. Oremland, R. S., J. S. Blum, C. W. Culberton, P. T. Visscher, L. G. Miller, P. Dowdle, and F. E. Strohmaier. 1994. Isolation, growth, and metabolism of an obligately anaerobic, selenate-respiring bacterium, strain SES-3. Appl. Environ. Microbiol. 60:3011-3019.

32. Pfennig, N. 1978. Rhodocyclus purpureus, gen. nov, and sp. nov., a ringshaped, vitamin $\mathrm{B}_{12}$-requiring member of the family Rhodospirillaceae. Int. J. Syst. Bacteriol. 28:283-288.

33. Pfennig, N., and H. Biebl. 1976. Desulfuromonas acetoxidans gen. nov. and sp. nov., a new anaerobic, sulfur-reducing, acetate-oxidizing bacterium. Arch. Microbiol. 110:3-12.

34. Rainey, F. A., R. Toalster, and E. Stackebrandt. 1993. Desulfurella acetivorans, a thermophilic, acetate-oxidizing and sulfur-reducing organism, represents a distinct lineage within the Proteobacteria. Syst. Appl. Microbiol. 16:373-379.

35. Rodriguez-Tomé, P., P. J. Stoehr, G. N. Cameron, and T. P. Flores. 1996 The European Bioinformatics Institute (EBI) databases. Nucleic Acids Res. 24:6-12.

36. Saitou, N., and M. Nei. 1987. The neighbor-joining method: a new method for reconstructing phylogenetic trees. Mol. Biol. Evol. 4:406-425.

37. Schumacher, W., P. M. H. Kroneck, and N. Pfennig. 1992. Comparative systematic study of "spirillum" 5175, Campylobacter and Wolinella species. Description of "spirillum" 5175 as Sulfurospirillum deleyianum gen. nov., sp. nov. Arch. Microbiol. 158:287-293.

38. Segerer, A. H., and K. O. Stetter. 1992. The order Sulfolobales, p. 684-701 In A. Balows, H. G. Trüper, M. Dworkin, W. Harder, and K. H. Schleifer (ed.), The prokaryotes, 2nd ed., vol. 1. Springer, New York, N.Y.

39. Simbert, R. M. 1984. Genus Campylobacter Sebald and Veron 1963, 907 AL p. 111-118. In N. R. Krieg and J. G. Holt (ed.), Bergey's manual of systematic bacteriology, vol. 1. The Williams \& Wilkins Co., Baltimore, Md.

40. Stackebrandt, E., and W. Liesack. 1993. Nucleic acid and identification, p. 151-194. In M. Goodfellow and A. G. O'Donnell (ed.), The new bacteria systematics. Academic Press, London, England.

41. Stolz, J. F., T. Gugliuzza, J. S. Blum, R. Oremland, and F. M. Murillo. 1997. Differential cytochrome content and reductase activity in Geospirillum barnesii strain SES3. Arch. Microbiol. 167:1-5.

42. Strunk, O., and W. Ludwig. 1996. ARB-Software Environment for Sequence Data. Technische Universität München, Munich, Germany.

43. Tamaoka, J., and K. Komagato. 1984. Determination of DNA base composition by reverse-phase high-performance liquid chromatography. FEMS Microbiol. Lett. 25:125-128.

44. Tindall, B. J. 1990. A comparative study of the lipid composition of Halobacterium saccharovorum from various sources. Syst. Appl. Microbiol. 13:128130.

45. Tindall, B. J. 1990. Lipid composition of Halobacterium lacusprofundi. FEMS Microbiol. Lett. 66:199-202.

45a.Tindall, B. J. Unpublished data.

46. Van de Peer, Y., S. Nicolaï, P. De Rijk, and R. De Wachter. 1996. Database on the structure of small ribosomal subunit RNA. Nucleic Acids Res. 24: $86-91$.

47. Widdel, F., and N. Pfennig. 1992. The genus Desulfuromonas and other gram-negative sulfur-reducing eubacteria, p. 3379-3389. In A. Balows, H. G. Trüper, M. Dworkin, W. Harder, and K. H. Schleifer (ed.), The prokaryotes, 2nd ed., vol. 4. Springer, New York, N.Y.

48. Wolfe, R. S., and N. Pfennig. 1977. Reduction of sulfur by spirillum 5175 and syntrophism with Chlorobium. Appl. Environ. Microbiol. 33:427-433.

49. Wolin, M. J., E. A. Wolin, and N. J. Jacobs. 1961. Cytochrome-producing anaerobe vibrio, Vibrio succinogenes sp. nov. J. Bacteriol. 81:911-917. 